\title{
XVII. Notice on the bichromate of the perchloride of chrome
}

\section{Walter}

To cite this article: M. Walter (1838) XVII. Notice on the bichromate of the perchloride of chrome, Philosophical Magazine Series 3, 12:71-72, 83-85, DOI: 10.1080/14786443808649381

To link to this article: http://dx.doi.org/10.1080/14786443808649381

曲 Published online: 01 Jun 2009.

Submit your article to this journal ๘

Џ Article views: 4

Q View related articles ¿ 
M. Walter on the Bichromate of Perchloride of Chrome. 83

two meridian planes passing through the perpendicular to that front, or, in other words, the intersection of a plane drawn through either ray belonging to a front perpendicular thereunto is always a line of vibration in that front.

This has been noticed, I think, by Sir William Hamilton for the particular case of the singular points.

As two fronts belong to every ray, so two rays pertain to every front. And from what has been said above it appears that the two lines of vibration in any front are the projections of its two rays upon its own plane.

XVII. Notice on the Bichromate of the Perchloride of Chrome. By $M$. WaLter *

I HAVE constantly succeeded in the preparation of this compound by employing the quantities and process following: I placed in a tubulated glass retort 100 parts of sea-salt dissolved, and 168 parts of neutral chromate of potash, the whole being well mixed and reduced to a very fine powder; I then fixed to the retort a tube and a receiver with two apertures, and poured by degrees, through a tube in the form of an $\mathrm{S}$, which was fixed in the aperture of the retort, 300 parts of concentrated sulphuric acid.

The liquor thus obtained is of a beautiful blood-red colour; it is volatile, and sends forth vapour copiously; when placed in contact with a quantity of water, it falls to the bottom in drops of an oily appearance, and changes into chlorhydric acid and chromic acid ; its boiling point is fixed and takes place at $118^{\circ}$ Cent. under the pressure of $0^{\mathrm{m} \cdot 76}$; its specific gravity at the temperature of $21^{\circ}$ Cent. is 1.71 ; it attacks mercury with great activity, for this reason all contact with this metal must be avoided; it is decomposed by sulphur, detonates with phosphorus, dissolves chlorine and iodine, and combines with ammonia with a disengagement of light. A small quantity mixed with concentrated alcohol combines with a violent explosion, and the inflamed alcohol is scattered with force. This unexpected action very nearly deprived me of my sight, and has burnt me in a most dreadful manner.

The bichromate of the perchloride of chrome is composed according to my analyses, of

$$
\begin{aligned}
& \text { Chlorine......... 45.14 } \\
& \text { Chrome ......... 35.58 } \\
& \text { Oxygen ......... 19.28 }
\end{aligned}
$$

This :esult agrees with that obtained by $\mathrm{H}$. Rose, and with a combination calculated according to the formula $2 \mathrm{Cr} \mathrm{O}^{3}+$ $\mathrm{Cr} \mathrm{O}^{6}$.

- From the Comptes Rendus, No. 22, and Ser. 1837.

$\mathrm{M} 2$ 
S4 M. Walter on the Bichromate of Perchloride of Chrome.

$$
\begin{aligned}
& \mathrm{Cr}^{3}=1055 \cdot 457=35 \cdot 37 \\
& \mathrm{Ch}^{6}=1327 \cdot 950=44 \cdot 51 \\
& \mathrm{O}^{6}=600 \cdot 000=20 \cdot 12
\end{aligned}
$$

The density of the vapour deduced from observation gives $\mathrm{D}=5.9$; the value obtained by calculation by means of the formula $2 \mathrm{Cr} \mathrm{O}^{3}+\mathrm{Cr}^{\mathrm{Ch}^{6}}$, is equal to $\mathrm{D}=5^{\cdot 48}$.

$$
\begin{array}{lr}
3 \text { vol. of chrome...... } & 11 \cdot 64.33 \\
6 \text { vol. of chlorine } \ldots & 14.6760 \\
6 \text { vol. of oxygen...... } & 6 \cdot 6156
\end{array}
$$

$$
\frac{32 \cdot 9349}{6}=5 \cdot 48
$$

The analysis and the density of the vapour of the bichromate of the perchloride of chrome coincide therefore in representing this body as a combination of chromic acid and perchloride of chrome; its constitution may however be regarded in a different light, which, without being in contradiction either to the composition or to the density found, explains in a certain degree better its remarkable characters and its little stability. Dr. Thomson having subjected this body at the time to analysis, had already offered quite a peculiar opinion on its constitution; he regarded it as being formed of chromic acid and of chlorine, and called it chloro-chromic acid;* but this opinion could not withstand the objection of $\mathrm{H}$. Rose, that with this supposition the combination mustcontain 10 per cent. more chlorine than obtained by analysis. But if instead of representing this combination as formed of chromic acid and chlorine, we look upon it as being formed of $\mathrm{Cr} \mathrm{O}^{2}$ and chlorine, the hypothetical radical $\mathrm{Cr}^{2} \mathrm{O}^{2}$ of chromic acid (itself expressed by the formula $\mathrm{Cr}^{2}+\mathrm{O}$ ), acting the part of a simple body similar to the oxide of carbon and to benzoyl, this combination becomes analogous to the chlorooxicarbonic acid, the chlorine occupying the place of the oxygen, which is not found in the radical of chromic acid. We may therefore represent this body by the formula $\mathrm{CrO}^{3}+\mathrm{Ch}$, which agrees both with the analysis and with the density found. Indeed the analysis calculated according to this formula gives the following result :

$$
\begin{aligned}
& 1 \text { atom of chrome } \ldots . . .351 \cdot 819=35 \cdot 37 \\
& 2 \text { atoms of chlorine..... } 44.2 \cdot 650=44 \cdot 51 \\
& 2 \text { atoms of oxygen ..... } 200 \cdot 000=20 \cdot 12 \\
& 994 \cdot 469
\end{aligned}
$$

* A notice of Dr. Thomson's researches will be found in Phil. Mag, and Annals, N. S. vol. i. p. 45\%,-Evir. 
And as to what concerns the density, calculated according to the same formula, we find

$$
\begin{aligned}
& 1 \text { vol. of chrome ...... } \\
& 2 \text { vol. of chlorine } \ldots .8411 \\
& 2 \text { vol. of oxygen ...... } \frac{2 \cdot 8920}{2 \cdot 2078} \\
& \frac{10 \cdot 9809}{2}=5.49
\end{aligned}
$$

But here each atom of the compound represents only two volumes of vapour. This body may therefore be regarded as a distinct acid, which might be named chloro-oxi-chromic acid. Recollecting that the perchloride of chrome does not exist in an isolated state, that analogous compounds are only produced by acids, which for one atom of radical contain three atoms of oxygen, which are isomorphous with each other, and which may all be expressed after the hypothesis of M. Persoz, by the formula $\mathrm{R} \mathrm{O}^{2}+\mathrm{O}$, in taking into consideration the facility with which this body is decomposed when brought into contact with other bodies, and its little stability; this manner of regarding the constitution of this body, which explains its various actions, offers the appearance of much probability.

XVIII. Observations on the Meteors of the 12th of November. Communicated by Prof. Forbes. *

A COMMITTEE appointed by the Physico-Mathematical A Society (University of Edinburgh) were employed on the nights of the 12th and 13th of November, in watching for the annual fall of meteors, expected to take place about that time. During the earlier part of the night of the 12th there was a fine coloured Aurora : at $7^{\mathrm{h}} 30^{\mathrm{m}}$, a red arch extended from E. to W.passing about $15^{\circ} \mathrm{S}$. of the zenith and within $15^{\circ}$ of the full moon. This continued with slight variations till $9^{\text {b }}$, when it stretched from $\mathrm{E}$. to $\mathrm{SW}$., there being a beautiful red spot at the point of radiation a little S. or SE. of the zenith. The red colour continued with variations till $10^{\mathrm{h}} 15^{\mathrm{m}}$, when the whole northern half of the sky was covered with bright greenish streamers. Soon after the sky became covered with clouds and mist, through which the brightest stars only were visible. There was scarcely any wind. Till late in the morning no meteors of any importance were seen. At $9^{\mathrm{h}} 35^{\mathrm{m}}$ one meteor shot from E. toward NNE., and at $10^{\mathrm{h}} 20^{\mathrm{m}}$ another from the zenith along meridian. At $0^{\mathrm{h}} 25^{\mathrm{m}}$ one passed from NNW.

* See our last volume, pp. 261,567 . 